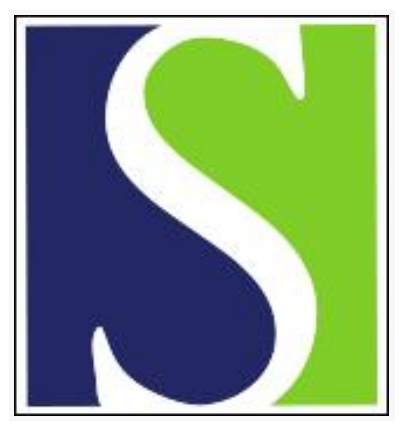

Scand J Work Environ Health 2005;31(2):152-159

https://doi.org/10.5271/sjweh.862

Issue date: Apr 2005

Effect of aging on performance, muscle activation and perceived stress during mentally demanding computer tasks by Alkjær T, Pilegaard M, Bakke M, Jensen BR

Affiliation: IFI/MAI, Panum Institute, University of Copenhagen, Blegdamsvej 3, DK-2200 Copenhagen N. brjensen@ifi.ku.dk

Key terms: age; aging; computer task; computer work; electromyography; mental demand; muscle activation; perceived stress; performance; self-assessment; self-rated stress; self-report

This article in PubMed: www.ncbi.nlm.nih.gov/pubmed/15864909 


\title{
Effect of aging on performance, muscle activation and perceived stress during mentally demanding computer tasks
}

\author{
by Tine Alkjær, PhD, ${ }^{1,2}$ Marianne Pilegaard, MSc, ${ }^{1}$ Merete Bakke, PhD, ${ }^{3}$ Bente $R$ Jensen, PhD ${ }^{1}$
}

\begin{abstract}
Alkjær T, Pilegaard M, Bakke M, Jensen BR. Effect of aging on performance, muscle activation and perceived stress during mentally demanding computer tasks. Scand J Work Environ Health 2005;31(2):152-159.

Objectives This study examined the effects of age on performance, muscle activation, and perceived stress during computer tasks with different levels of mental demand.

Methods Fifteen young and thirteen elderly women performed two computer tasks [color word test and reference task] with different levels of mental demand but similar physical demands. The performance (clicking frequency, percentage of correct answers, and response time for correct answers) and electromyography from the forearm, shoulder, and neck muscles were recorded. Visual analogue scales were used to measure the participants' perception of the stress and difficulty related to the tasks.

Results Performance decreased significantly in both groups during the color word test in comparison with performance on the reference task. However, the performance reduction was more pronounced in the elderly group than in the young group. Likewise, a higher level of self-reported stress was found for the elderly participants after the color word test. During the reference task higher electromyographic levels and reported difficulty were recorded for the elderly group than for the young group.

Conclusions The findings suggest that mental demands affect young and elderly women differently. Thus the mentally demanding computer task had a more pronounced effect on the elderly than on the young. In contrast to the results in the reference task, the same level of muscle activity for most muscles and the same level of selfreported difficulty was found in the two groups during the color word test. The elderly probably compensated for age-related changes by reducing their work speed markedly.
\end{abstract}

Key terms age; computer work; electromyography; mental demand; performance; self-rated stress.

Computers are commonly used at workplaces and at home in modern society. The proportion of elderly persons, as well as elderly computer users, is already large and is expected to increase significantly in the forthcoming decades. Consequently, the literature on aging and human-computer interaction has been increasing over the past several years (1-7).

Very often computer work involves the use of a computer mouse. Such computer tasks are challenging for the motor control system, since the demands for precision, muscle coordination, and work speed are high (3, 4 ). The control of a computer mouse among people with little or no experience with using a computer mouse has been found to be more difficult for older people than for younger ones (1). Furthermore, a study among experienced computer users has shown that performance during different computer mouse tasks with low mental demand is slower and less accurate among elderly computer users than among younger ones, when the demand for precision is high or during double-clicking with the computer mouse (3). In addition, higher muscle activity during computer work with low mental demand has been observed for the elderly, possibly because of the increased effort needed to meet the demands for precision in this group (3). These age-related differences in performance and muscle activity may be a result of the decline in motor control ability associated with aging (8). Changes in brain structures (9), muscle composition (1012 ), proprioception (13), and the ability to integrate information from different receptors (14-16) may account for most of the impairment of motor performance with age.

Recently, it has been shown that, among younger people, performance is impaired and muscle activity levels increase during a mentally demanding computer task

Institute of Exercise and Sport Sciences, University of Copenhagen, Copenhagen, Denmark. Institute of Medical Anatomy, Panum Institute, University of Copenhagen, Copenhagen, Denmark. Section of Clinical Oral Physiology, School of Dentistry, University of Copenhagen, Copenhagen, Denmark.

Correspondence to: Dr Bente R Jensen, IFI/MAI, Panum Institute, University of Copenhagen, Blegdamsvej 3, DK-2200 Copenhagen N. [E-mail: brjensen@ifi.ku.dk] 
that requires high precision and fast movements when compared with a reference task (17). Yet, it is unclear how such a mentally demanding computer task affects the performance and level of muscle activity in the elderly. Information about differences in performance and muscle activation between the young and elderly during mentally demanding computer work is highly relevant, not only in relation to the adjustment, development, improvement and use of input devices and software, but also regarding the understanding of age-related differences in movement control during stressful situations.

Accordingly, the purpose of our study was to examine the effect of aging on performance, muscle activation, and perceived stress during computer tasks with different levels of mental demand.

\section{Study population and methods}

\section{Study population}

A total of 28 healthy participants, 15 young [24.5 (0.9) years] and 13 elderly [63.5 (0.9) years] women, participated. In order to eliminate a potential age-related difference in learning effect in the study, all the participants were frequent and experienced computer users. Thus the younger women had used a computer regularly for $7.4(0.8)$ years, and the elderly women had used one for 13.3 (2.4) years. All the participants were righthanded, and in a questionnaire all reported that they had no history of musculoskeletal disorders. Elevated blood pressure and pregnancy were exclusion criteria. The participants gave their written informed consent to participate in the experiment, which was approved by the local ethics committee.

\section{Tactile finger threshold}

The tactile pressure threshold was measured on the digital pulps of the index and the middle fingers of the right hand by Semmes-Weinstein monofilaments (Touch-Test Sensory Evaluators, North Coast Medical, San Jose, CA, USA) $(18,19)$. First, the middle of the digital pulp was marked with a pencil. The participants were instructed to look the other way while the touch test was performed. Furthermore, the participants were asked to indicate when they could feel the filament applied to the skin. The filament was gently placed on the mark, while the force was increased until the filament bended. Then, the filament was slowly lifted from the skin. The threshold was determined as the thinnest filament size felt in at least two of three trials, and the size was converted into target force in newtons according to the calibration chart provided by the manufacturer.

\section{Procedure}

During the experiment the participants sat on an office chair, which was individually adjusted with respect to height, back support, and distance to the computer table. The computer table was adjusted to support both forearms properly. A computer mouse and a mouse mat were placed one length of the forearm from the front edge of the table. The computer screen [17-inch (43.2 $\mathrm{cm})$, Liteon, Litepanel 150, resolution $1024 \times 768$ pixels] was placed in front of the participants and the top of the screen was aligned with their eyes. The distance between the screen and their eyes was measured for each participant. The average distance for all the participants was 65.0 (SD 0.8 ) $\mathrm{cm}$ with no difference between the groups. A custom-made vision test confirmed that all the participants were able to see and read Times New Roman font characters at font sizes from 11 to 5 on the computer screen.

With the right hand, the participants were asked to perform two different tasks on the computer with the computer mouse. Prior to the tasks, they were carefully instructed and were allowed to practice until they felt familiar with the tasks. Each of the two tasks lasted 20 minutes, and the task sequence was randomized. There was a 30-minute break for relaxation between the tasks. During the break the participants were allowed to relax, read, chat, and visit the rest room.

\section{Tasks}

The two tasks were designed to represent different levels of mental demand but the same physical demand: (i) a computer version of the Stroop color word test and (ii) a reference task developed for a previous study (17, 20). The color word test served as a mental stress model (21) in which the participants were exposed to a high level of mental demand. In short, during the task, one of the Danish words for "red", "green", "blue", or "yellow" was shown on the computer screen in random order and at different positions. The letters appeared in a color different from the color indicated by the word. Below the color word, four icons $(7 \times 11 \mathrm{~mm})$ were labeled with the color words in black and always in the same order. The participants were asked to report the color of the word by clicking on the corresponding icon. The color words were shown in random order and at random time intervals at a machine-determined pace, which had an average of 1.3 (range 0.6-2.0) seconds. The participants were instructed to answer as quickly and correctly as possible. An alarm signal (beep) sounded if the answer was either wrong or not given within the scheduled time interval. The color word test is known to elicit a stable cardiovascular response over time as a response to mental demand (21). 
During the reference task the participants were asked to click on an icon that appeared on the screen at the same positions and with the same time intervals as in the color word test. Thus the physical demands in the reference task and color word test were similar. None of the participants had any previous experience with either the color word test or the reference tasks.

\section{Performance}

The performance of the two tasks was evaluated as the clicking frequency (number of mouse clicks per minute), the percentage of correct answers, and the mean response time for correct answers. The clicking frequency was calculated based on $3 \times 5$-minute recordings, which corresponded to the periods in which electromyography was recorded. The percentage of correct answers and the mean response time for correct answers were calculated for the whole 20-minute test period.

\section{Visual analogue scales}

Before and after performing the two tasks, the participants were asked to mark how mentally stressed they felt on a $100-\mathrm{mm}$ horizontal visual analogue scale (VAS). The self-rated stress level was expressed as the percentage, for which $0 \%$ indicated "no stress during the task" (left end point) and 100\% indicated "the highest stress imaginable during the task" (right end point). In addition, immediately after the tasks were finished, the participants were asked to mark the perceived difficulty on another VAS, on which the left end point $(0 \%)$ corresponded to "not difficult at all" and the right end point $(100 \%)$ corresponded to "very difficult".

\section{Electromyography}

Surface electrodes were mounted $2 \mathrm{~cm}$ apart over the most prominent part of the muscle belly on the following muscles: extensor digitorum (ED), flexor carpi radialis (FCR), the descending part of trapezius muscle (TRAP), and the neck extensor muscle group (NECK), all on the right side of the body. Before the bipolar surface electrodes (720 01-K, Neuroline, Medicotest, Denmark) were mounted, the skin was carefully shaved and rinsed with alcohol. The raw electromyographic (EMG) signals were filtered $(10-450 \mathrm{~Hz})$ and sampled at 1024 Hz. During the 20-min periods of the two tasks, the EMG signals were recorded for three periods of 5 minutes. The recordings started after 2 minutes and $3 \times 5$ minutes were subsequently sampled with 1 minute in between. The EMG signals were corrected for EMG activity, recorded while the participants were relaxed in a supine position. The root mean square of each of the 5-minute EMG recordings (rms-EMG) was calculated using intervals of $100 \mathrm{~ms}$. Then, the EMG signals of the two tasks were normalized to the maximal EMG values obtained during isometric maximal voluntary contractions $(\mathrm{MVC})$ of the shoulder muscles $(3 \times$ bilateral shoulder elevation), neck extensors $(3 \times$ neck extension), wrist extensors and flexors $(3 \times$ handgrip, $3 \times$ wrist extension, $3 \times$ wrist flexion, $3 \times$ finger extension and $3 \times$ ulnar deviation). [For details see Laursen et al (17).] The maximal rms-EMG values of the MVC were calculated using a 1 -second moving averaging window. The mean rms-EMG amplitudes were calculated. Furthermore, the amplitude probability distribution function (APDF) was determined, and hence the static muscle activity (the 10th percentile level, P0.1, ie, the level exceeded $90 \%$ of the time) was calculated. Finally, the percentage of time with EMG gaps (percentage of total recording time) was calculated. EMG gaps were defined as periods with an activity of $<0.5 \%$ of the maximal EMG for at least 0.2 seconds (22).

The time course patterns of the ED and FCR muscles were calculated by averaging the EMG signals in a period from 500 milliseconds before to 500 millliseconds after each mouse click. In this case, 20-millisecond intervals were used to calculate the rms-EMG values. Furthermore, the co-contraction (percentage of the co-contraction) between the ED and FCR muscles around the mouse click (ie, 500 milliseconds before and after the clicks) was calculated. Briefly, the percentage of the co-contraction $=[2 \mathrm{C} /(\mathrm{A}+\mathrm{B})] \times 100 \%$, where $\mathrm{C}$ is the common area of the rms-EMG curves for the ED and FCR calculated by integration and A and B are the total areas of the rms-EMG curves for each of the two muscles (23).

There were no statistical differences between the three 5-minute EMG recordings. Accordingly, all of the EMG parameters presented were calculated as means of the $3 \times 5$-minute EMG recordings during the two tasks.

The exerted forces during the maximal isometric contractions (handgrip, wrist extension, finger extension, and bilateral shoulder elevation) were measured, and muscle strength was calculated for each type of contraction as the highest 1 -second value obtained.

\section{Statistics}

A two-way analysis of variance was used to test the effect of age and task on performance and the EMG data. In case of significance for the interaction between age and task, a post-hoc test was performed. A paired t-test was used to compare VAS values before and after the tasks. A two-sample t-test was used to compare VAS values, muscle strength, and tactile pressure threshold between the groups. The level of significance was set at $5 \%$. All of the results are presented as means and the standard error of the means. 
Table 1. Maximal volunatry contraction during maximum handgrip, wrist extension, finger extension, and shoulder elevation force for the young $(\mathrm{N}=15)$ and elderly $(\mathrm{N}=13)$ women.

\begin{tabular}{|c|c|c|c|c|c|c|c|c|c|c|}
\hline & \multicolumn{10}{|c|}{ Maximal voluntary contractions } \\
\hline & \multicolumn{2}{|c|}{$\begin{array}{l}\text { Handgrip } \\
\text { (N) }\end{array}$} & \multicolumn{2}{|c|}{$\begin{array}{l}\text { Wrist extension } \\
\text { (N) }\end{array}$} & \multicolumn{2}{|c|}{$\begin{array}{l}\text { Finger extension } \\
\text { (N) }\end{array}$} & \multicolumn{2}{|c|}{$\begin{array}{l}\text { Shoulder elevation } \\
\text { (right) (N) }\end{array}$} & \multicolumn{2}{|c|}{$\begin{array}{l}\text { Shoulder elevation } \\
\text { (left) (N) }\end{array}$} \\
\hline & Mean & SE & Mean & SE & Mean & SE & Mean & SE & Mean & SE \\
\hline Young group & $336.2^{\mathrm{a}}$ & 11.5 & 111.2 & 4.2 & $68.4^{b}$ & 4.5 & $505.2^{b}$ & 25.3 & 505.9 a & 34.9 \\
\hline Elderly group & $295.4^{\mathrm{a}}$ & 14.0 & 105.4 & 5.1 & $55.6^{b}$ & 2.7 & $426.5^{b}$ & 23.3 & $441.0^{a}$ & 25.6 \\
\hline
\end{tabular}

a Tendency towards difference between young and elderly women.

${ }^{b}$ Significant difference between young and elderly women.

\section{Results}

\section{Muscle strength and tactile finger threshold}

The handgrip strength, finger extension strength, and elevation strength of the right shoulder were 12\%, 19\% and $16 \%$ lower, respectively, for the elderly group than for the young group (table 1). For the left shoulder a tendency towards a difference was found, while, for wrist extension, no difference in muscle strength was found between the groups. The tactile pressure threshold was higher for the elderly participants [0.32 (SE 0.04) N for the index finger; 0.30 (SE 0.04) $\mathrm{N}$ for the middle finger] than for the young participants $[0.06(\mathrm{SE} 0.03) \mathrm{N}$ for the index finger; 0.12 (SE 0.03) $\mathrm{N}$ for the middle finger].

\section{Performance}

During the color word test, the elderly women were $32 \%$ slower than the young women, while during the reference task the elderly women were $9 \%$ slower than the young women (figure 1). Compared with that of the reference task, the clicking frequency in the color word test was less reduced for the young group (8 clicks/minute) than for the elderly group ( 15 clicks/minute) $(\mathrm{P}=0.005)$. The young women had a higher percentage of correct answers (40\% for the color word test and $15 \%$ for the reference task) $(\mathrm{P}=0.004)$ and a shorter mean response time for correct answers (19\% for the color word test and $13 \%$ for the reference task) $(\mathrm{P}=0.002)$ than the elderly women. In addition, the difference between the response time of the color word test and the reference task was larger for the elderly women $[0.29$ (SE 0.03$)$ seconds] than for the young women [0.19 (SE 0.02) seconds] $(\mathrm{P}=0.045)$.

\section{Self-reported stress and level of task difficulty}

Similar levels of self-reported stress were found for the two groups initially before the reference task [6.3 (SE 1.2 )\% for the young; 5.8 (SE 1.9)\% for the elderly] and before the color word test [5.0 (SE 1.4)\% for the young; 6.2 (SE 2.3)\% for the elderly]. In addition, no difference was found for the self-reported stress level of the young [12.6 (SE 2.1)\%] and elderly [16.4 (SE 4.2)\%] after the reference task. However, the stress level reported after the color word test approached significance between the two groups, young [40.3 (SE 6.2)\%] versus elderly [57.8 (SE 6.0)\%] $(\mathrm{P}=0.05)$. Furthermore, the stress level after the color word test was higher in both age groups when compared with that of the reference task $(\mathrm{P}=0.000)$.

The elderly group reported a higher level of difficulty after the reference task [28.2 (SE 4.8)\%] than the
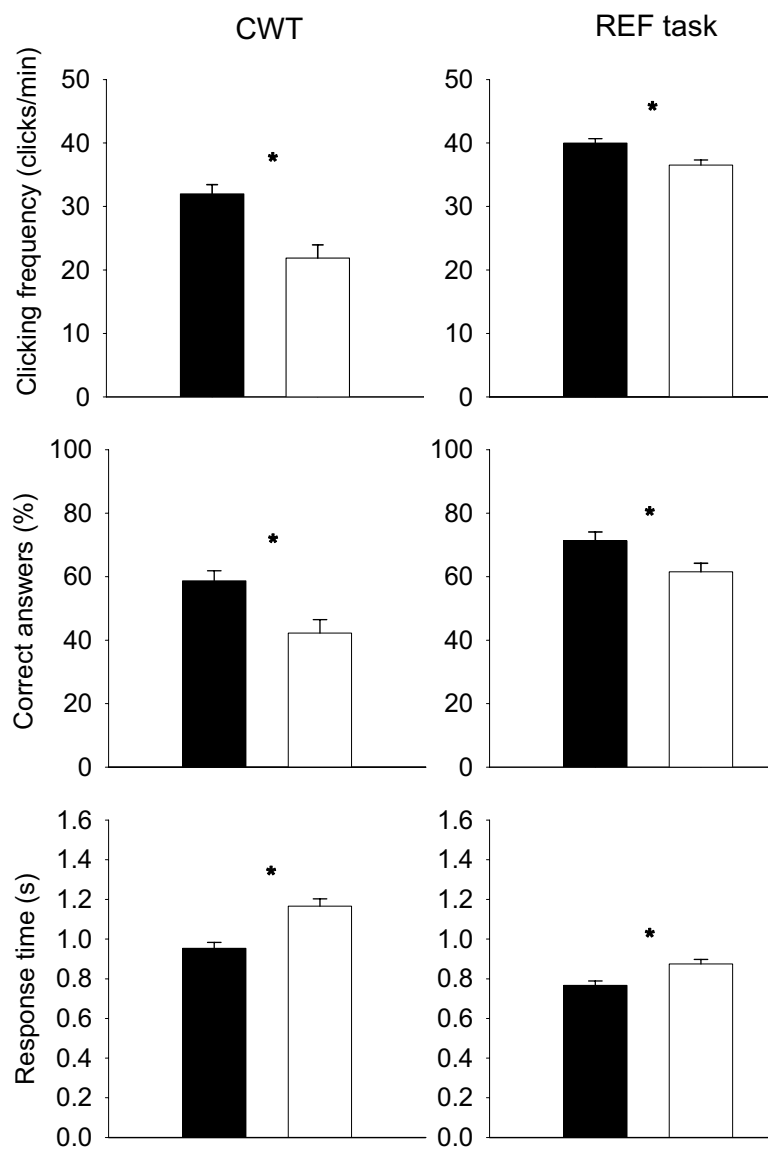

Figure 1. Results of the color word test (CWT) and the reference task (REF task) of the young (black bars, $\mathrm{N}=15$ ) and elderly (white bars, $\mathrm{N}=13$ ). Values are means and standard errors of the means. Asterisks indicate significant differences between the groups. 
young group [14.0 (SE 2.6)\%] ( $\mathrm{P}=0.019)$. In contrast, the reported levels of difficulty after the color word test task were similar in the young [66.8 (SE 6.1) \%] and the elderly [75.7 (SE 4.7) \%] groups.

\section{Electromyography}

Generally, higher rms-EMG levels were measured for the elderly than for the young in both tasks for the shoulder-neck region (TRAP: $\mathrm{P}=0.005$, NECK: $\mathrm{P}=0.07$ ) (figure 2). Thus the average differences between the muscle activity in the elderly and the young group corresponded to $2.1 \%$ of the EMGmax. The rms-EMG of the forearm muscles reflected a different response to the tasks between the groups (ED: $\mathrm{P}=0.000$, FCR: $\mathrm{P}=0.011$ ). The rms-EMG of the ED and the FCR muscles increased significantly between the reference task and the color word test of the young women, while the rms-EMG of the ED decreased from the reference task to the color word test, and, for the FCR muscle, the rms-EMG level was similar between the tasks among the elderly. Furthermore, the post-hoc test showed that the rms-EMG of the

CWT

REF task

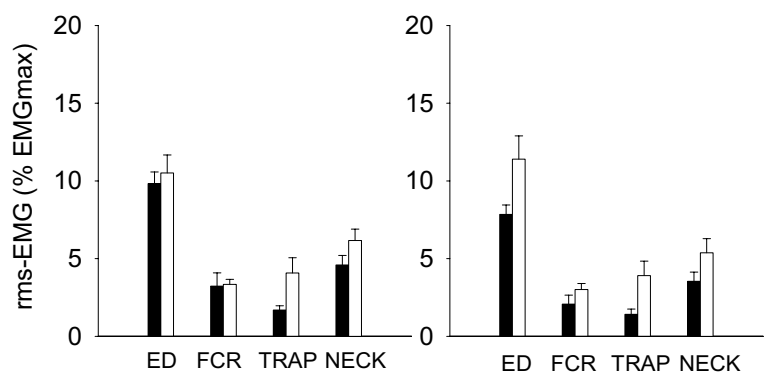

Figure 2. Root mean square in the electromyography (\%EMGmax) of the extensor digitorum (ED), flexor carpi radialis (FCR), trapezius (TRAP) and the neck extensor (NECK) muscles during the color word test (CWT) and the reference task (REF task) of the young (black bars, $\mathrm{N}=15$ ) and elderly (white bars, $\mathrm{N}=13$ ). Values are means and standard errors of the means. For significant differences see the text.
ED was higher for the elderly than for the young during the reference task $(\mathrm{P}=0.03)$, while no corresponding difference was observed in the color word test.

The static EMG activity levels of the FCR and the TRAP muscles during the tasks were significantly higher for the elderly than for the young (table 2) (FCR: $\mathrm{P}=0.001$, TRAP: $\mathrm{P}=0.044)$. The static $\mathrm{EMG}$ activity levels of the forearm muscles reflected a different response to the tasks between the groups (ED: $\mathrm{P}=0.002, \mathrm{FCR}$ : $\mathrm{P}=0.002)$. Thus the static EMG activity increased significantly more from the reference task to the color word test among the young than among the elderly (table 2).

In general, the percentage of time with gaps for the FCR muscle tended to be significantly lower for the elderly than for the young ( $\mathrm{P}=0.098)$ (table 2$)$. There was a significant decrease in the percentage of time with gaps for the FCR and the TRAP muscles from the reference task to the color word test in both groups (table 2). No time periods with gaps were observed in the EMG of the ED.

The time course patterns of the EMG activity of the ED and FCR muscles were almost identical between the groups and tasks (figure 3). The EMG peaks were observed close to the click. The peak activity of the FCR muscle was the most pronounced and easiest to identify for all the participants. On the average, the peak activity of the FCR muscle was observed 0.07 seconds prior to the click. The peak activity of the ED muscle varied more between the participants. However, for most of the participants the peak activity of the ED muscle was observed just after the click (figure 3 ). There were no differences between the young and the elderly regarding the peak activity of the FCR and ED muscles in the color word test. Nor were there any differences in the peaks for the FCR and the ED muscles in the reference task, although the mean activity of the ED was significantly higher for the elderly (figures 2 and 3). The peak amplitude for the FCR and the ED increased significantly from the reference task to the color word test in the young group, but not in the elderly group. The

Table 2. Static electromyographic level (P0.1) and gaps (\% total time) of the extensor digitorum, flexor carpi radialis, trapezius (right) and neck extensor muscles in the color word test (CWT) and the reference (REF) task for the young $(\mathrm{N}=15)$ and elderly $(\mathrm{N}=13)$ women.

\begin{tabular}{|c|c|c|c|c|c|c|c|c|c|c|c|c|c|c|c|c|}
\hline \multirow[t]{3}{*}{ Task } & \multicolumn{4}{|c|}{ Extensor digitorum muscle } & \multicolumn{4}{|c|}{ Flexor carpi radialis muscle } & \multicolumn{4}{|c|}{ Trapezius muscle (right) } & \multicolumn{4}{|c|}{ Neck extensor muscles } \\
\hline & \multicolumn{2}{|c|}{$\begin{array}{l}\text { Static electro- } \\
\text { myography } \\
\text { (P0.1) }\end{array}$} & \multicolumn{2}{|c|}{$\begin{array}{l}\text { Gaps } \\
\text { (\% total } \\
\text { time) }\end{array}$} & \multicolumn{2}{|c|}{$\begin{array}{l}\text { Static electro- } \\
\text { myography } \\
\text { (P0.1) }\end{array}$} & \multicolumn{2}{|c|}{$\begin{array}{l}\text { Gaps } \\
\text { (\% total } \\
\text { time })\end{array}$} & \multicolumn{2}{|c|}{$\begin{array}{l}\text { Static electro- } \\
\text { myography } \\
\text { (P0.1) }\end{array}$} & \multicolumn{2}{|c|}{$\begin{array}{l}\text { Gaps } \\
(\% \text { total } \\
\text { time })\end{array}$} & \multicolumn{2}{|c|}{$\begin{array}{l}\text { Static electro- } \\
\text { myography } \\
\text { (P0.1) }\end{array}$} & \multicolumn{2}{|c|}{$\begin{array}{c}\text { Gaps } \\
\text { (\% total } \\
\text { time) }\end{array}$} \\
\hline & Mean & SE & Mean & SE & Mean & SE & Mean & SE & Mean & SE & Mean & SE & Mean & SE & Mean & SE \\
\hline \multicolumn{17}{|l|}{ Color word test } \\
\hline $\begin{array}{l}\text { Young group } \\
\text { Elderly group }\end{array}$ & $\begin{array}{l}6.4 \\
6.8\end{array}$ & $\begin{array}{l}0.5 \\
1.0\end{array}$ & $\begin{array}{l}0.0 \\
0.0\end{array}$ & $\begin{array}{l}0.0 \\
0.0\end{array}$ & $\begin{array}{l}1.0 \\
1.8\end{array}$ & $\begin{array}{l}0.1 \\
0.2\end{array}$ & $\begin{array}{l}4.0 \\
0.1\end{array}$ & $\begin{array}{l}1.9 \\
0.1\end{array}$ & $\begin{array}{l}0.9 \\
2.1\end{array}$ & $\begin{array}{l}0.2 \\
0.6\end{array}$ & $\begin{array}{c}19.8 \\
7.2\end{array}$ & $\begin{array}{l}7.7 \\
3.8\end{array}$ & $\begin{array}{l}3.2 \\
4.1\end{array}$ & $\begin{array}{l}0.5 \\
0.6\end{array}$ & $\begin{array}{l}0.4 \\
0.2\end{array}$ & $\begin{array}{l}0.3 \\
0.2\end{array}$ \\
\hline \multicolumn{17}{|l|}{ Reference } \\
\hline $\begin{array}{l}\text { Young group } \\
\text { Elderly group }\end{array}$ & $\begin{array}{l}5.0 \\
7.2\end{array}$ & $\begin{array}{l}0.4 \\
1.2\end{array}$ & $\begin{array}{l}0.0 \\
0.0\end{array}$ & $\begin{array}{l}0.0 \\
0.0\end{array}$ & $\begin{array}{l}0.7 \\
1.7\end{array}$ & $\begin{array}{l}0.1 \\
0.2\end{array}$ & $\begin{array}{c}13.7 \\
0.0\end{array}$ & $\begin{array}{l}5.1 \\
0.0\end{array}$ & $\begin{array}{l}0.9 \\
2.1\end{array}$ & $\begin{array}{l}0.2 \\
0.7\end{array}$ & $\begin{array}{l}29.1 \\
11.6\end{array}$ & $\begin{array}{l}9.1 \\
4.1\end{array}$ & $\begin{array}{l}2.5 \\
3.8\end{array}$ & $\begin{array}{l}0.5 \\
0.7\end{array}$ & $\begin{array}{l}2.3 \\
4.2\end{array}$ & $\begin{array}{l}1.8 \\
3.8\end{array}$ \\
\hline
\end{tabular}




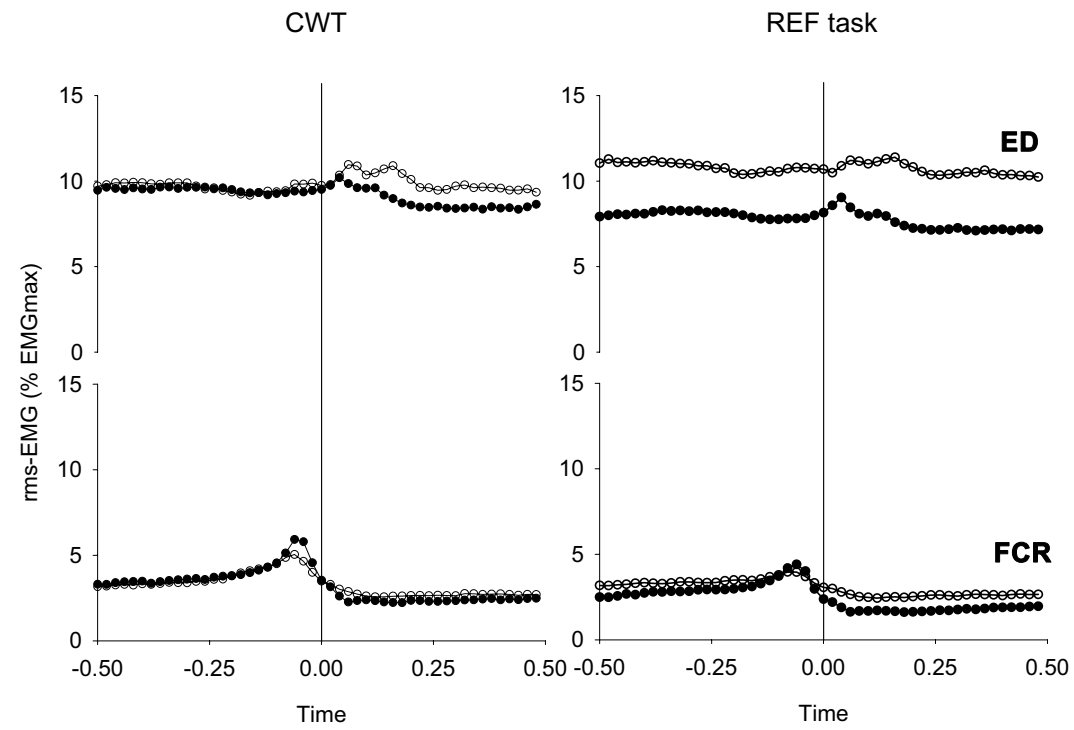

$\longrightarrow$ Young $(\mathrm{N}=15)$ Elderly $(\mathrm{N}=13)$
Figure 3. Averaged time course patterns of the root mean square of the electrographic signals 500 milliseconds before and after the clicks (indicated by the vertical line) of the extensor digitorum (ED) and flexor carpi radialis (FCR) muscles during the color word test (CWT) and the reference task (REF task). The young group $(\mathrm{N}=15)$ is represented by black dots and the elderly group $(\mathrm{N}=13)$ by open circles. percentage of co-contraction between the ED and FCR muscles increased significantly from the reference task to the color word test $(\mathrm{P}=0.025)$, but no difference was observed between the age groups (table 3 ).

\section{Discussion}

One major finding of our study was that the mentally demanding color word test had a more pronounced effect on the performance of the elderly group than on that of the young group. Thus the mean response time for correct answers was more prolonged among the elderly women during the color word test than during the reference task when compared with that of the young women. Likewise, the differences in clicking frequency and the percentage of correct answers between the color word test and the reference task were greater for the elderly women than for the young women. The percentage of correct answers and the response time for correct answers for the young women during the color word test and reference task corresponded to the findings of a recent study (17). For the elderly women, our study showed a pronounced decrease in the percentage of correct answers and a prolongation of the response time from those of the young women when mental demand was added to the computer work, in spite of a marked decrease in work speed (clicking frequency) among the elderly women. Previous studies have shown that elderly people move more slowly and less accurately than young persons $(8,24-26)$ and that the reaction time of the elderly is prolonged due to a general slowing of decision-making processes in the central nervous system $(27,28)$. The impairment of performance during the color word test among the elderly in our study, in spite
Table 3. Co-contraction based on electromyography from the extensor digitorum muscle relative to the flexor carpi radialis muscle.

\begin{tabular}{lccccc}
\hline Task & \multicolumn{3}{c}{$\begin{array}{c}\text { Co-contraction extensor digitorum muscle } \\
\text { per flexor carpi radialis muscle (\%) }\end{array}$} \\
\cline { 2 - 3 } \cline { 5 - 6 } \cline { 5 - 6 } & \multicolumn{2}{c}{ Young group } & & \multicolumn{2}{c}{ Elderly group } \\
\cline { 2 - 3 } \cline { 5 - 6 } & Mean & SE & & Mean & SE \\
\hline Color word test & 44.6 & 5.2 & & 51.3 & 6.0 \\
Reference & 42.0 & 5.7 & & 46.0 & 5.1 \\
\hline
\end{tabular}

of equally frequent computer mouse practice as that of the young, may therefore be explained by a combined effect of an age-related decline in motor performance ability and a slowing of the signal processing in the central nervous system. In addition, the higher levels of tactile perception threshold for the elderly participants may have contributed to their slower and less accurate performance.

The difficulty for the elderly group to meet the combined demand for fast decision making and precision during the color word test was reflected in the subjective responses as a higher self-reported stress level when compared with that of the young. In contrast, no agerelated differences in perceived stress were found either after the less demanding reference task or initially before the computer tasks. Thus the age-related difference in the induced stress level seems to be dependent on task complexity. Correspondingly, the elderly have reported a greater perceived workload for a mentally challenging accounts-balancing task than the younger participants, while older participants experienced less stress than younger ones during an information retrieval task involving a socially interactive telephone component (2).

In line with the data on stress level during the color word test, one can expect a higher level of self-reported difficulty among the elderly group than among the young 
group. However, the results showed no age-related difference in the perceived difficulty during the color word test. This finding may be explained by the pronounced reduction in work speed (clicking frequency) in the color word test relative to that of the reference task for the elderly even though they were encouraged to follow the pre-determined work speed, as guided by the computer program. Thus an age-related elevated level of perceived stress among the elderly women, when compared with the young women, was found during the color word test in spite of a slower work speed among the elderly.

The level of co-contraction in the forearm increased from the reference task to the color word test, and this increment may be related to the increased complexity of the task. The EMG levels (mean or static) of the ED, FCR, and TRAP muscles in the reference task were significantly higher among the elderly than among the young. The increased muscle activity in the elderly may reflect an increased co-activation of the muscles to stabilize the upper extremity and thereby help to meet the demands for precision. However, an adverse effect of increased co-activation may be a reduction of the ability to perform fast acceleration. It has been suggested that the elderly reduce the variability of their movements by increasing muscle co-activation (29). In our study no differences in the co-contraction values, based on the ED and FCR activity, were observed between the groups although differences in the static EMG activity and the mean activity levels were found.

In addition to the activation of the forearm muscles, also co-activation of the masseter and temporal muscles has been found during the computer tasks (30). This coactivation has been the most pronounced in elderly participants. A recent study has shown that the motor neurons to the FCR and the extensor carpi radialis muscles are facilitated during voluntary teeth clenching (31). A facilitatory effect of the masticatory muscles may therefore have contributed to the higher levels of forearm muscle activity in the elderly in our study when compared with that of the young participants during the reference task.

The muscle activity patterns of the ED, FCR, and NECK muscles were characterized by a low percentage of time with EMG gaps across both the groups and the tasks. The percentage of time with EMG gaps of the FCR muscle tended to be lower for the elderly than for the young participants in both the color word test and the reference task. Furthermore, the percentage of time with EMG gaps for the FCR and the TRAP muscles was significantly lower during the color word test than during the reference task. It has been suggested that there is an association between EMG gaps and the rotation of motor unit recruitment (ie, a high gap frequency possibly prevents the overload of the muscle fibers) (32).
In addition, studies have suggested that few EMG gaps may contribute to the development of work-related musculoskeletal symptoms $(22,33)$. The occurrence of few EMG gaps during computer work has also been reported by others $(3,17)$. Together with the findings in the our study, this finding may indicate that prolonged computer work, especially if it contains time pressure and requires high precision, may increase the risk of symptoms in the upper extremities. Therefore, it seems important to be aware of the high precision demand and time pressure during computer use.

Among the young participants the EMG activity of the forearm muscles increased with increasing mental demands. This result concurs with the findings reported by Laursen et al (17), who observed significantly higher EMG activity levels in young participants performing the color word test in comparison with the reference condition. The elderly were simply not able to manage to click on the icon within the predetermined response time limit during the color word test, which may tend to decrease the level of muscle activation and thereby counteract a potential effect of mental demand on muscle activation level. Our finding of unchanged muscle activity in most of the muscles from which values were recorded among the elderly during the color word test, compared with the reference task, does not justify any conclusion regarding the effect of mental demand on muscle activity level but, rather, that, at the same level of muscle activation, performance was reduced when mental demand was added. However, the co-contraction between the forearm muscles was significantly increased in the color word test for both the young and the elderly; this finding may indicate that cocontraction is an appropriate measure of the effect of mental demand on muscle activation.

In conclusion, the relationship between aging and the mental demands induced by computer mouse work was studied. The findings suggest that mental demands affect young and elderly women differently. Thus the mentally demanding computer mouse task had a more pronounced effect, in terms of a larger reduction in performance and a higher reported stress level, in the elderly group than in the young group. As opposed to the reference task, in the color word test, the same level of muscle activity for most muscles, as well as the same level of self-reported task difficulty, was found for the two groups; the elderly probably compensated for the agerelated changes by markedly reducing their work speed.

\section{Acknowledgments}

The authors would like to thank the Danish Research Agency for its financial support. 
We would also like to acknowledge the assistance of Dr Anette Tuxen, Section of Clinical Oral Physiology, School of Dentistry, University of Copenhagen, with the perception threshold measurements.

\section{References}

1. Smith MW, Sharit J, Czaja SJ. Aging, motor control, and the performance of computer mouse tasks. Hum Factors 1999; 41:389-96.

2. Sharit J, Czaja SJ, Sankaran NN, Hoag DW, Leonard DC, Dilsen EK. Subjective experiences of stress, workload, and bodily discomfort as a function of age and type of computer work. Work Stress 1998;12:125-44.

3. Laursen B, Jensen BR, Ratkevicius A. Performance and muscle activity during computer mouse tasks in young and elderly adults. Eur J Appl Physiol 2001;84:329-36.

4. Laursen B, Jensen BR. Shoulder muscle activity in young and older people during a computer mouse task. Clin Biomech 2000;15 Suppl 1:S30-S33.

5. Czaja SJ, Sharit J. Age differences in attitudes toward computers. J Gerontol B Psychol Sci Soc Sci 1998;53:329-40.

6. Czaja SJ, Sharit J. Age differences in the performance of computer-based work. Psychol Aging 1993;8:59-67.

7. Sharit J, Szaja SJ. Ageing, computer-based task performance, and stress: issues and challenges. Ergonomics 1994;37(4):55977.

8. Ketcham CJ, Stelmach GE. Age-related declines in motor control. In: Birren JE, Schaie KW, editors. Handbook of the psychology of aging. 5. ed. San Diego (CA): Academic Press; 2001. p 313-48.

9. Alexander GE. Basal ganglia thalamocortical circuits-their role in control of movements. J Clin Neurophysiol 1994; 11:420-31.

10. Doherty TJ, Vandervoort AA, Brown WF. Effects of ageing on the motor unit: a brief review. Can J Appl Physiol 1993; 18:331-58.

11. Campbell MJ, McComas AJ, Petito F. Physiological changes in ageing muscles. J Neurol Neurosurg Psychiatry 1973; 36:174-82.

12. Larsson L, Ramamurthy B. Aging-related changes in skeletal muscle: mechanisms and interventions. Drugs Aging 2000; 17:303-16.

13. Stelmach GE, Sirica A. Aging and proprioception. Age 1986; 9:99-103.

14. Chaput S, Proteau L. Aging and motor control. J Gerontol B Psychol Sci Soc Sci 1996;51:346-55.

15. Chaput S, Proteau L. Modifications with aging in the role played by vision and proprioception for movement control. Exp Aging Res 1996;22:1-21.

16. Larsson L. Motor units: remodeling in aged animals. J Geron- tol A Biol Sci Med Sci 1995;50 special number:91-5.

17. Laursen B, Jensen BR, Garde AH, Jørgensen AH. Effect of mental and physical demands on muscular activity during the use of a computer mouse and a keyboard. Scand J Work Environ Health 2002;28(4):215-21.

18. Patel MR, Bassini L. A comparison of five tests for determining hand sensibility. J Reconstr Microsurg 1999;15:523-6.

19. Massy-Westropp N. The effects of normal human variability and hand activity on sensory testing with the full SemmesWeinstein monofilaments kit. J Hand Ther 2002;15:48-52.

20. Stroop JR. Studies of interference in serial verbal reactions. J Exp Psychol 1935;18:643-62.

21. Hoshikawa Y, Yamamoto Y. Effects of stroop color-word conflict test on the autonomic nervous system responses. Am Physiol Soc 1997;1113-21.

22. Veiersted KB, Westgaard RH, Andersen P. Pattern of muscle activity during stereotyped work and its relation to muscle pain. Int Arch Occup Environ Health 1990;62:31-41.

23. Winter DA. Biomechanics and motor control of human movement. 2nd ed. New York, Chichester, Brisbane, Toronto, Singapore: John Wiley \& Sons, Inc; 1990.

24. Gottsdanker R. Age and simple reaction time. J Gerontol 1982;37:342-8.

25. Ketcham CJ, Seidler RD, Van Gemmert AW, Stelmach GE. Age-related kinematic differences as influenced by task difficulty, target size, and movement amplitude. J Gerontol B Psychol Sci Soc Sci 2002;57:54-64.

26. Brocklehurst JC, Robertson D, Jamesgroom P. Clinical correlates of sway in old-age-sensory modalities. Age Ageing 1982;11:1-10.

27. Fozard JL, Vercruyssen M, Reynolds SL, Hancock PA, Quilter RE. Age-differences and changes in reaction-time-the Baltimore longitudinal-study of aging. J Gerontol 1994; 49:179-89.

28. Cerella J. Information-processing rates in the elderly. Psychol Bull 1985;98:67-83.

29. Seidler-Dobrin RD, He J, Stelmach GE. Coactivation to reduce variability in the elderly. Motor Control 1998;2:314-30.

30. Bakke M, Tuxen A, Thomsen CE, Bardow A, Alkjær T, Jensen BR. Salivary cortisol level, salivary flow rate, and maticatory muscle activity in response to acute mental stress: a comparison between aged and young women. Gerontology 2004;50:383-92.

31. Takahashi T, Ueno T, Ohyama T. Modulation of $\mathrm{H}$ reflexes in the forearm during voluntary teeth clenching in humans. Eur J Appl Physiol 2003;90:651-3.

32. Westgaard RH, De Luca CJ. Motor unit substitution in longduration contractions of the human trapezius muscle. J Neurophysiol 1999;82:501-4.

33. Veiersted KB, Westgaard RH, Andersen P. Electromyographic evaluation of muscular work pattern as a predictor of trapezius myalgia. Scand J Work Environ Health 1993;19:284-90.

Received for publication: 16 March 2004 